\title{
Verbal short-term memory and motor speech processes in Broca's aphasia
}

\author{
C. Goerlich', I. Daum', I. Hertrich ${ }^{2}$ and H. Ackermann² \\ 1/nstitute of Medical Psychology and Behavioral Neurobiology and ${ }^{2}$ Department of Neurology, \\ University of Tübingen, Germany
}

Correspondence to: H. Ackermann, Department of Neurology, University of Tübingen, HoppeSeyler-Str. 3, 72076 Tübingen, Germany

\begin{abstract}
The present study investigated the relationship between verbal short-term memory and motor speech processes in healthy control subjects and five patients suffering from Broca's aphasia. Control subjects showed a phonological similarity effect, a word length effect and an articulatory suppression effect, supporting the hypothesis of a phonological store and an articulatory loop component of short-term memory. A similar effect of phonological similarity was observed in the aphasic patients, while the effects of word length and articulatory suppression were reduced. In control subjects, measures of short-term memory were correlated to measures of motor speech rate only if speech rate was assessed in more complex conditions (such as sentence rather than syllable repetition). There was also evidence of an association of speech impairment and short-term memory deficits in the aphasic patients.
\end{abstract}

Keywords: Short-term memory - Broca's aphasia - Apraxia of speech

\section{INTRODUCTION}

The relationship between motor speech processes and phonological encoding has been an important issue in recent research on short-term memory. Within this context, Baddeley (1990) has proposed a working memory model in which a discrete cognitive subsystem, the so-called articulatory or phonological loop, regulates the processing of speech-based information. According to this model, the phonological loop consists of two components, a passive phonological store and an articulatory rehearsal process based on inner speech. The latter subsystem is assumed to prevent loss of information due to passive decay by continually reactivating the memory traces within the phonological store (e.g. Vallar and Baddeley, 1984; Baddeley, 1986). Auditory stimuli are thought to have an obligatory and direct access to the phonological input system. With visual presentation, however, an additional operation becomes necessary. This process involves articulatory rehearsal converting the visual material into a phonological code before registering it in the phonological store (Baddeley, 1990).

The Baddeley working memory model rests mainly on data from studies of span performance and speech-based short-term memory phenomena in normal subjects. There are several lines of research in this area. Firstly, evidence for the role of phonologi-

(C) 1995 Rapid Science Publishers cal encoding and storage is provided by the so-called phonological similarity effect. This effect describes the finding that normal subjects recall fewer sequences of items that are phonologically similar as compared to items that are dissimilar in this regard because the latter are less confusable in memory (Conrad and Hull, 1964). The effect holds for visual as well as auditory presentation; therefore it appears not to be primarily based on acoustic perception (see Della Sala et al., 1991).

The word length effect is a source of evidence for the operation of the articulatory rehearsal process. This phenomenon reflects temporal features of articulatory rehearsal and refers to the finding that the memory span for words depends on the speed with which the words can be spoken (Baddeley et al., 1975).

Further support for an involvement of articulation in short-term memory stems from experiments where subjects are asked to perform a simple speech task (like uttering "the the the...") while simultaneously listening to sequences of verbal items during encoding. This procedure reduces verbal spans, abolishes word length effects with both auditory and visual presentation, and phonological similarity effects with visual, but not with auditory presentation (for a 
summary see Waters et al., 1992). These effects, known as articulatory suppression, are thought to be based on a disruption of rehearsal operations in healthy subjects (Baddeley et al., 1984). Articulatory suppression does not reflect impaired attention, because non-articulatory tasks (such as concurrent tapping) have no or little effect on short-term memory performance (Baddeley et al., 1984; see also Baddeley, 1990).

Selective short-term memory deficits have been observed without any concomitant deficits in speech (e.g. Shallice and Warrington, 1974; Shallice and Butterworth, 1977; Vallar and Baddeley, 1984). The investigation of anarthric patients, on the other hand, has yielded normal short-term memory performance with preserved sensitivity to word length and phonological similarity effects in spite of a severe articulatory disorder (Baddeley and Wilson, 1985). These findings suggest that the supposed articulatory rehearsal process may be independent of motor speech execution (Baddeley and Wilson, 1985; Baddeley, 1990).

Damage to the anterior language area of the dominant hemisphere may give rise to a specific speech production disorder called cortical dysarthria (Whitty, 1964), apraxia of speech (Buckingham, 1991) or aphemia (Schiff et al., 1983). Compared to anarthria, apraxia of speech represents a higher order articulatory deficit in terms of impaired speech motor programming (for a summary see Buckingham, 1991). Detailed analysis of short-term memory in patients with apraxia of speech revealed an absence of the word length effect (Waters et al., 1991, 1992). This finding has been interpreted as evidence for a dysfunctional articulatory loop. Patients with apraxia of speech as a group also failed to show phonological similarity effects. Waters and co-workers (1991) considered this finding as evidence for an additional impairment in the phonological store.

Apraxia of speech rarely occurs as an isolated syndrome. Most often this type of articulatory deficit can be observed in connection with Broca's aphasia. Since Broca's aphasia often includes deficient phonological processing (Caplan, 1987), the missing phonological similarity effects should characterize this syndrome rather than apraxia of speech. A recent study by Vallar and co-workers (1992) assessed auditory and visual short-term memory in a mixed group of aphasic patients, but the analyses did not comprise a separate evaluation of the short-term memory performance of Broca aphasics. One major aim of the present study was to determine the specific profile of short-term memory dysfunction in Broca's aphasia. Deficient word length effects and reduced articulatory suppression effects in the presence of normal phonological similarity effects would characterize an impairment at the level of articulatory rehearsal in aphasic patients; an additional lack of phonological similarity effects would indicate a combined deficit in the phonological store and the articulatory rehearsal process.

Even though articulatory rehearsal in the context of short-term memory is assumed to be based on inner rather than overt speech, some authors have postulated a relationship between these rehearsal processes and articulatory rate (Waters et al., 1991), and memory spans for words were found to be related to speech tempo (Baddeley et al., 1975). Hence a second objective of the present study was to investigate the correlation of different speech rate parameters (spontaneous speech, various repetition tasks) with short-term memory performance.

\section{METHODS}

\section{Subjects}

Five patients with Broca's aphasia participated in this study (patients A.K., G.T., H.L., B.R., L.B.). Mean age was 52.8 years (S.D. 12.0); two subjects were male. All patients had suffered from an ischemic infarction within the distribution of blood supply of the left middle cerebral artery as demonstrated by cranial computed tomography. Besides aphasic disturbances, all patients had presented with right-sided hemiparesis in the acute stage. In four patients, cerebral thrombosis was suggested to be the etiological factor of ischemia. In the remaining patient, a cardiac embolic mechanism was assumed.

The present assessment was performed on average 4.9 years after stroke (S.D. 4.5), including an evaluation of the aphasic disorder by means of a standard German language examination [Aachener Aphasie Test (AAT); Huber et al., 1983]. This test allows the classification and quantification of standard and non-standard aphasic syndromes (global aphasia, amnestic aphasia, Wernicke's and Broca's aphasia, conduction aphasia, transcortical aphasias).

According to AAT criteria, Patient H.L. was classified as suffering from mild Broca's aphasia with dysgraphic and apraxic components. B.R. had mild to moderate Broca's aphasia. Patient L.B. manifested moderate Broca's aphasia with apraxic components. Patients A.K. and G.T. both suffered from moderate Broca's aphasia.

Formal language testing indicated clearly that all individuals had adequate speech comprehension for participation in the study; in particular, they were able to understand the task instructions. 


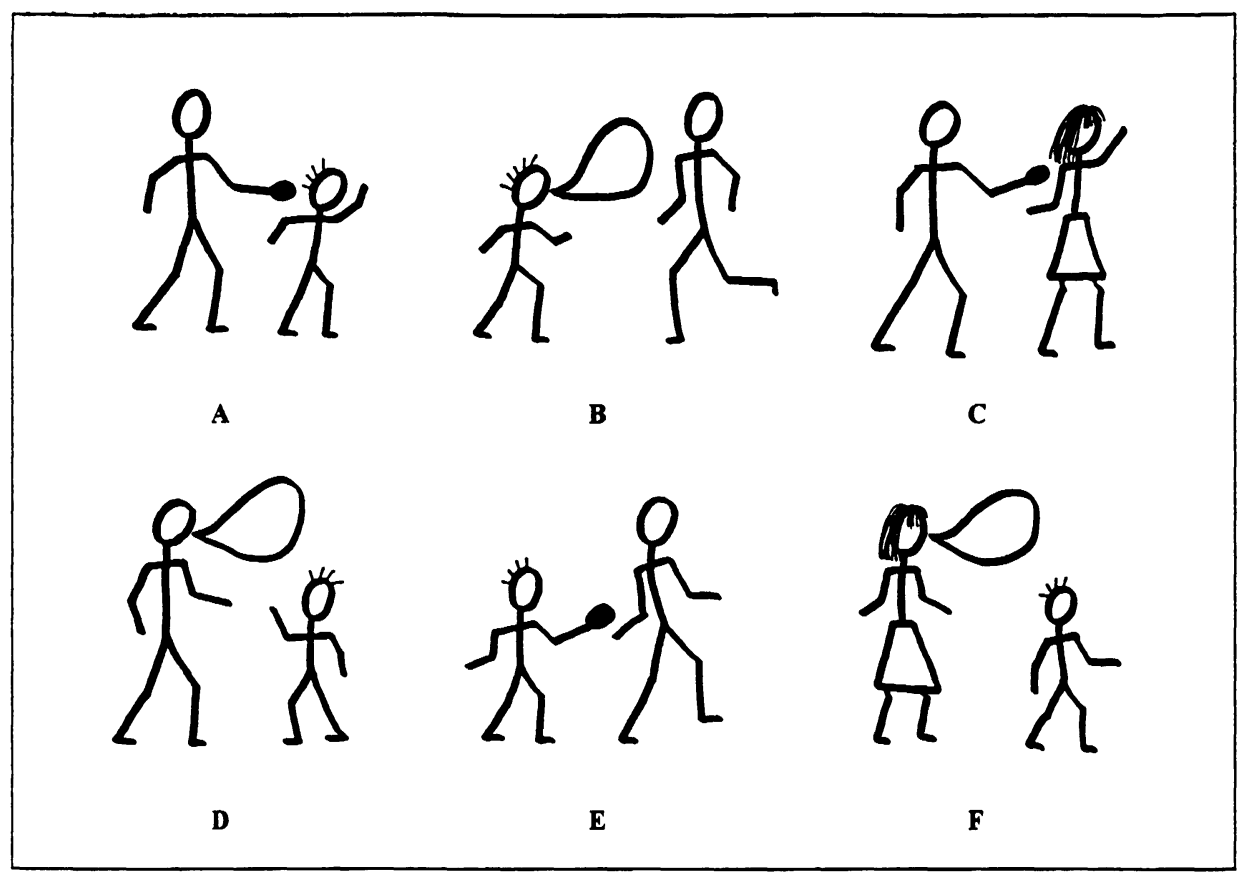

FIG. 1. Example from the sentence comprehension test. The subject has to point to the picture corresponding to the sentence read by the examiner.

Control data were collected from 10 healthy volunteers recruited by advertisement [five men and five women, mean age 55.4 years (S.D. 12.9)]. Patients and controls were comparable with respect to age $[t(13)=-0.38, p=0.714]$. All patients and control subjects were right-handed.

Verbal informed consent was obtained from all subjects prior to testing. All participants received a small reimbursement for their expenses.

\section{Short-term memory}

Auditory and visuospatial short-term memory were assessed by means of the standard digit span [Wechsler Adult Intelligence Scale-Revised (WAIS-R); Wechsler, 1981] and Corsi Blocks tests (see Milner, 1971), respectively, using both forward and backward reproduction. In the digit span task, subjects have to verbally reproduce series of numbers read out by the experimenter. The Corsi Blocks tests require reproduction of a sequence of spatial positions tapped out by the examiner on a board of randomly ordered wooden blocks.

\section{Phonological similarity effect}

The phonological similarity effect was studied using letter sequences involving two sets of seven letters each, the names of which were phonologically similar (for example, $b / b e, d / d e$ ) or phonologically dissimilar (for example, $\mathrm{q} / \mathrm{ku}, \mathrm{x} / \mathrm{iks}$ ) in the German language (see Baddeley, 1990). Two sequences of two to nine letters were generated at random. Subjects were asked to verbally reproduce the orally presented letter sequences.

\section{Word length effect}

In order to examine the word length effect, random sequences of two to seven different words consisting of one, two or three syllables were devised. All words were concrete common German nouns of similar frequency. The test was performed both with oral and visual presentation of the stimuli. Different lists of words were used in the two conditions. During oral presentation, the words were read by the experimenter. With visual presentation, the items were presented in upper case letters on cards. No word was repeated within any string.

\section{Articulatory suppression}

The effect of articulatory suppression upon verbal short-term memory was assessed by asking subjects to perform a concurrent articulatory or non-articulatory motor task during the encoding interval of a digit and a word span test, respectively. For the word span test, one-syllable words matched for frequency were used. The articulatory task consisted of sustained repetition of the syllable "tra", the nonarticulatory task of finger tapping. 


\section{Sentence comprehension}

In order to test the effect of semantic and syntactic constraints upon sentence comprehension (see Waters et al., 1991), two different tasks were administered. In the first test, the subjects were required to repeat eight meaningful and eight meaningless five-word sentences. The latter were derived from the former sentences by mixing the content words of the various sentences, resulting in syntactically identical sentences. Each correct reproduction scored one point.

The second task was administered in accordance with the procedure described by Heilman et al. (1976). Sixteen sentences were generated from a set of five major lexical units (man, woman, child, to hit, to call). Half of the sentences were simple active (e.g. "The man is hitting the child"), the other half were simple passive (e.g. "The woman is being called by the child"). After the presentation of each sentence, six line drawings (for an example see Fig. 1) were shown, and the subject was instructed to point to the picture representing the respective sentence proposition. Each correct sentence-picture association scored one point.

\section{Paired associate learning}

The Paired Associates Subtest of the Wechsler Memory Scale (Böcher, 1963) was administered in order to assess verbal learning. This test involves six related word pairs (such as "north-south") and four unrelated pairs (such as "cabbage-pen") and three learning trials.

\section{Assessment of speech rate}

In order to obtain several speech rate parameters four different speech tasks were performed.

Syllable repetition task. Each subject was asked to repeat each of the syllables "ka", "pa" and "ta", as fast as possible for the duration of a breath. This task is thought to represent a sensitive test of articulatory impairment (e.g. Gentil, 1990). It was chosen here in order to specifically assess the motor component of non-fluent speech in Broca's aphasics. The mean duration of the syllables 2 to 11 of the syllable repetition trains was assessed to estimate speech rate.

Articulation test sentences. Nonsense target words conforming to the sequence "geC1VC2e" were embedded in the German carrier phrase "Ich habe... gehört" ("I have heard..."). Using the two substitution rules: " $\mathrm{C} 1, \mathrm{C} 2=\{/ \mathrm{p} /, / \mathrm{t} /, / \mathrm{k} /\}$ " and " $\mathrm{V}=\{/ \mathrm{i} /$, $/ \mathrm{u} /, / \mathrm{y} /, / \mathrm{a} /\} ", 12$ test sentences can be derived (see Ackermann and Ziegler, 1991). The examiner presented the twelve test sentences orally in quasi- randomized order. Subjects were asked to repeat each sentence. These sentences were chosen in order to obtain a parameter of speech rate during a standardized condition. The mean duration of five syllabic segments ("ab", "eg", "eC1", "VC2", "eg") of the articulation test sentences served to assess speech rate. Syllabic segments were defined from vowel onset to vowel onset (see Ackermann and Hertrich, 1993).

Propositional sentences. Since preliminary analyses of the patient data presented here yielded evidence of a specific problem with nonsense material, a repetition task was added which comprised seven syntactically identical four-word sentences containing real words [e.g. "Ich hatte Papier geschnitten" ("I had cut paper")]. A segment ranging from the first vowel onset of the second word to the first vowel onset of the final word was used for the estimation of speech rate in terms of mean syllable duration. The initial and the final parts of the sentences were excluded from analysis because of the considerable degree of between-subject variability in the control group.

Spontaneous speech. A short interview was performed about the subject's place of residence and profession. Five segments were selected from this material that were not interrupted by any kind of dysfluency or pauses such as hesitations, vowel lengthening or stuttering. The segments contained, depending on each subject's speaking behaviour, 4 to 16 syllables.

\section{Procedure}

Testing was performed in a quiet room in the hospital or the subject's home. Each patient was tested on two separate occasions. The order of test presentation was held constant across subjects.

The lists for the assessment of the different spans (e.g. digit span, word span) were read to the subjects by the experimenter at a rate of about one item per second, beginning with sequences of two items and increasing until errors occurred. As soon as the last item of each sequence was read, the subject attempted to recall the list in the correct serial order. Testing was discontinued when both item lists of a given length were repeated incorrectly. For all lists, spans were defined as the last sequence for which at least one example of that particular length could be correctly reproduced.

The speech material was recorded using a DAT recorder (Sony PCM 2000, Japan) and a headmounted microphone (AKG C410, Austria). The mouth-microphone distance was about $5 \mathrm{~cm}$. Prior to analysis, the recordings were band-pass filtered 
MEMORY AND SPEECH PROCESSES IN BROCA'S APHASIA

TABLE I. Performance on the serial recall tasks

\begin{tabular}{ccccc}
\hline Subject & $\begin{array}{c}\text { Verbal span } \\
\text { forward }\end{array}$ & $\begin{array}{c}\text { Verbal span } \\
\text { backward }\end{array}$ & $\begin{array}{c}\text { Corsi Blocks } \\
\text { forward }\end{array}$ & $\begin{array}{c}\text { Corsi Blocks } \\
\text { backward }\end{array}$ \\
\hline Patients & & & & \\
A.K. & 4 & 4 & 6 & 5 \\
G.T. & 5 & 3 & 6 & 5 \\
H.L. & 3 & 2 & 5 & 4 \\
B.R. & 4 & 3 & 4 & 2 \\
L.B. & 3 & 2 & 4 & 4.2 \\
Mean & 3.8 & 2.8 & 5.0 & 1.3 \\
S.D. & 0.8 & 0.8 & 1.0 & \\
Controls & & & & 5.9 \\
Mean & 7.0 & 4.9 & 5.6 & 1.3 \\
S.D. & 1.2 & 1.0 & 1.0 & \\
\hline
\end{tabular}

Note: number of correctly recalled sequences.

$(50-4000 \mathrm{~Hz})$, digitized at a sampling rate of $10 \mathrm{kHz}$, and stored on a personal computer.

Acoustic analysis was performed by means of commercially available software (Computerized Speech Lab CSL 4300; Kay Elemetrics Corp., USA). For segmentation the speech signal was displayed on a PC monitor screen using a horizontal resolution of $1 \mathrm{~ms}$ and a maximal vertical resolution of $16 \mathrm{bit}$. The acoustic events considered for analysis were visually identified, with the support of auditory playback, and marked by a cursor. Syllable durations were measured from vowel onset to vowel onset (see Ackermann and Hertrich, 1993). For spontaneous speech, a similar procedure was used; the number of syllables was determined by the number of visible and audible vowel onsets.

\section{RESULTS}

\section{Short-term memory}

Memory span data are presented in Table I for the individual patients and the control group. Short-term memory performance was analyzed in a 2 (group) $\times$ 2 (modality: verbal vs visuospatial) ANOVA for forward and backward reproduction separately. For forward reproduction, there was a significant main effect of group $[\mathrm{F}(1,13)=18.9, p=0.001]$, but no effect of modality. More importantly, the interaction was significant $[F(1,13)=13.8, p=0.003]$. Separate analyses for the two modalities revealed that the aphasic patients showed diminished verbal spans as compared to control subjects $[t(13)=-5.5$, $p<0.001$ ], but did not differ significantly in their performance on the Corsi Blocks tests $[t(13)=-1.1$, $p=0.282]$. Within-group analyses showed that normal controls performed better on verbal span than on the Corsi Blocks tests $[t(9)=3.1, p=0.013]$, while the aphasic patients showed the reverse pattern of performance $[t(4)=-3.2, p=0.033]$.

Analysis of backward reproduction revealed significant main effects of group $[\mathrm{F}(1,13)=16.6, p=$ $0.001]$ and modality $[\mathrm{F}(1,13)=8.6, p=0.012]$. The interaction was not significant. Inspection of the data indicates that the controls performed better than the patients and the visuospatial spans were better than the verbal spans.

Thus, as predicted, patients with Broca's aphasia had reduced memory spans for verbal material. They also showed diminished spans in a visuospatial task when they had to recall the sequences in reverse order. On forward reproduction, the aphasic patients showed normal spans, indicating that there was no general visuospatial span deficit.

\section{Phonological similarity effect}

Performance of the aphasic patients and control subjects on the phonological similarity tasks is depicted in Fig. 2. The effect of phonological similarity was analyzed in a 2 (group) $\times 2$ (similarity type) ANOVA. The main effects of group and similarity type were significant [both $F(1,13)=24.5$, $p<0.001]$, but the interaction did not reach significance. While the aphasic subjects performed at an overall lower level of accuracy on both tasks, both patients and controls showed comparable phonological similarity effects.

\section{Word length effect}

Figure 3 shows the performance of the aphasic patients and control subjects on the word length tasks. These data were analyzed by means of a 2 (group) $\times 2$ (modality: verbal vs visual) $\times 3$ (word length) ANOVA. The analysis revealed significant main effects of group $[\mathrm{F}(1,13)=23.3, p<0.001]$ and word 


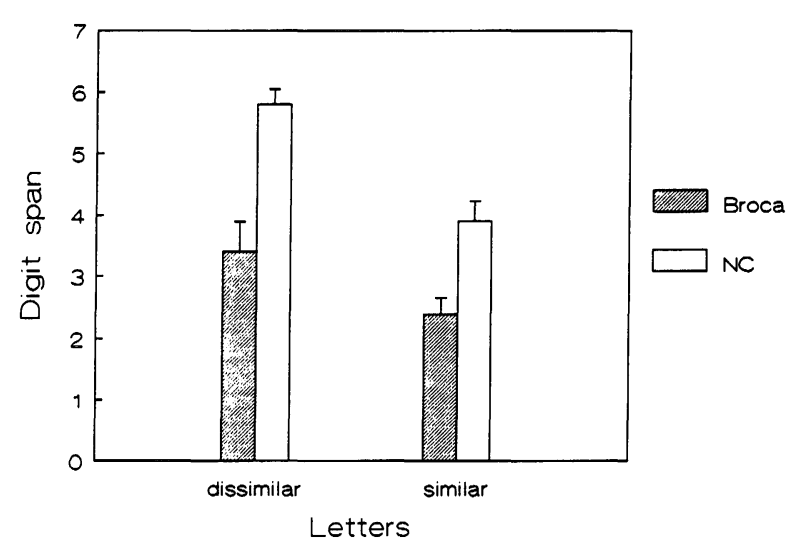

FIG. 2. Mean number (and S.E.M.s) of items recalled by patients suffering from Broca's aphasia (Broca) and control subjects (NC) on the phonological similarity task.
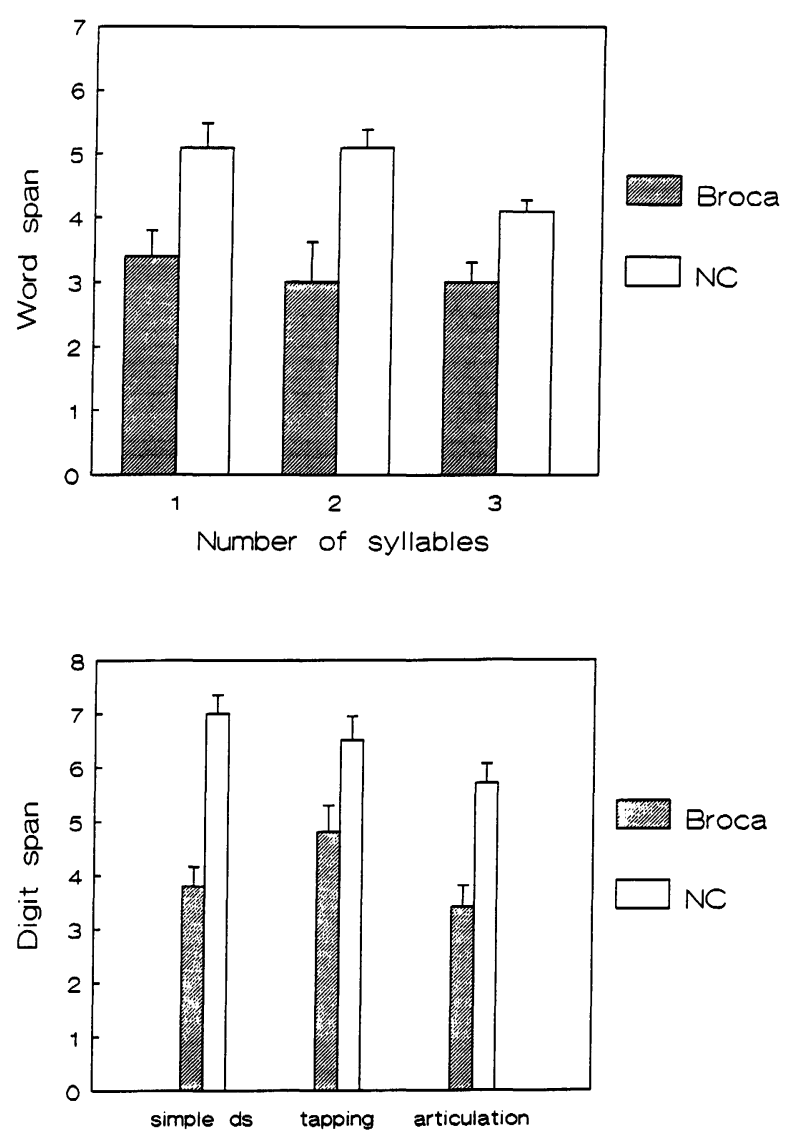

FIG. 3. Mean number (and S.E.M.s) of items recalled by patients suffering from Broca's aphasia (Broca) and control subjects (NC) in the auditory (top) and visual (bottom) word length tasks, respectively.

length $[F(2,26)=8.2, p=0.002]$, but not for modality. The interaction between group and word length was significant $[\mathrm{F}(2,26)=5.48, p=0.010]$; the performance of the control subjects decreased with in-
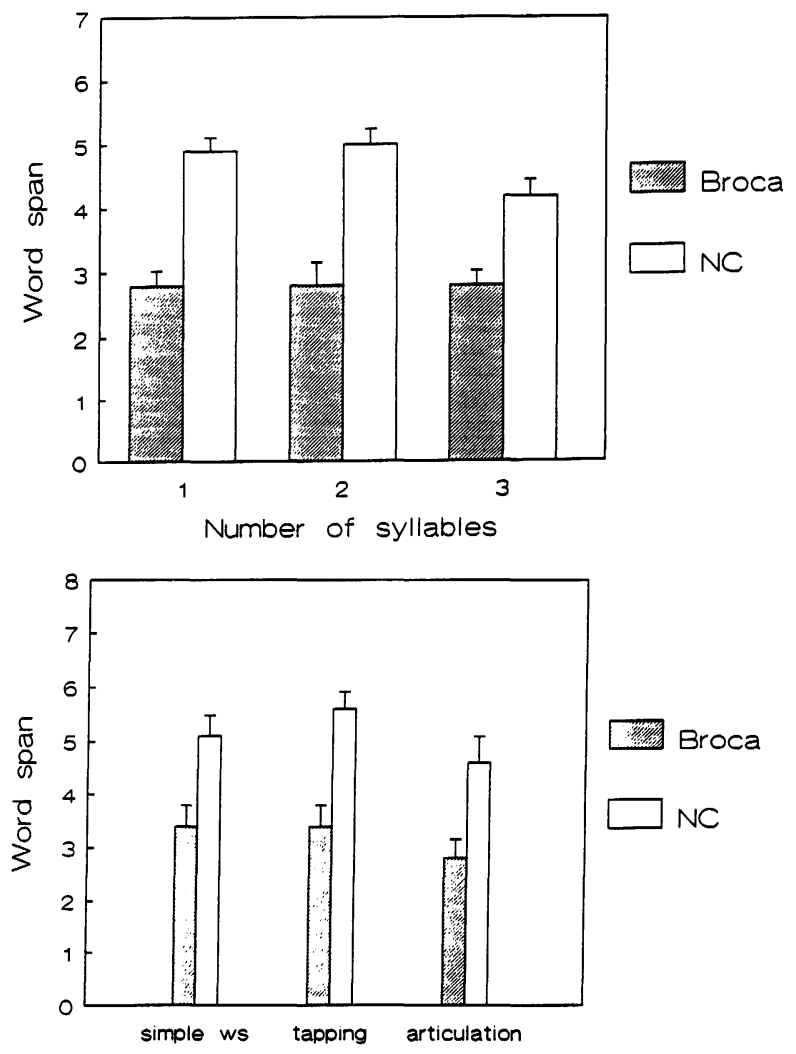

FIG. 4. Mean number (and S.E.M.s) of items recalled by patients suffering from Broca's aphasia (Broca) and control subjects (NC) in the articulatory suppression tasks using digits (top) or words (bottom), respectively.

creasing word length, whereas no such effect was seen in the aphasics.

\section{Articulatory suppression effect}

The findings for the aphasic patients and control subjects on the articulatory suppression tasks are shown in Fig. 4. The effect of articulatory suppression was analyzed in a 2 (group) $\times 3$ (distraction type: no distraction vs concurrent tapping vs concurrent articulation) ANOVA, separately for digits and words.

For digits, a significant interaction between group and distraction type emerged $[\mathrm{F}(2,26)=4.8, p=$ $0.016]$. While control subjects performed poorer with concurrent articulation relative to the no distraction condition, no such effect was seen in the aphasic patients. The spans of aphasic patients were best when they used rhythmic tapping as an encoding aid.

Analysis of articulatory suppression effects in the word span condition revealed significant main effects of group $[\mathrm{F}(1,13)=21.6, p<0.001]$ and distraction type $[\mathrm{F}(2,26)=3.8, p=0.035]$; the interaction was not significant. Performance with concurrent tapping was significantly better than performance with concur- 
MEMORY AND SPEECH PROCESSES IN BROCA'S APHASIA

TABLE II. Sentence comprehension

\begin{tabular}{ccccc}
\hline Subject & $\begin{array}{c}\text { Active } \\
\text { phrases }\end{array}$ & $\begin{array}{c}\text { Passive } \\
\text { phrases }\end{array}$ & $\begin{array}{c}\text { Meaningful } \\
\text { phrases }\end{array}$ & $\begin{array}{c}\text { Meaningless } \\
\text { phrases }\end{array}$ \\
\hline Patients & & & & \\
A.K. & 8 & 6 & 6 & 5 \\
G.T. & 8 & 7 & 8 & 6 \\
H.L. & 8 & 7 & 8 & 7 \\
B.R. & 4 & 2 & 8 & 0 \\
L.B. & 5 & 1 & 0 & 0 \\
Controls & & 8.0 & 8.0 & 8.0 \\
Mean & 8.0 & 0 & 0 & 0 \\
S.D. & 0 & & & \\
\hline
\end{tabular}

TABLE III. Paired associate learning

\begin{tabular}{|c|c|c|c|c|c|c|}
\hline \multirow[t]{2}{*}{ Subject } & \multicolumn{3}{|c|}{ Related pairs } & \multicolumn{3}{|c|}{ Unrelated pairs } \\
\hline & Trial 1 & Trial 2 & Trial 3 & Trial 1 & Trial 2 & Trial 3 \\
\hline \multicolumn{7}{|l|}{ Patients } \\
\hline $\begin{array}{l}\text { Mean } \\
\text { S.D. }\end{array}$ & $\begin{array}{l}3.2 \\
1.8\end{array}$ & $\begin{array}{l}5.2 \\
0.4\end{array}$ & $\begin{array}{l}5.4 \\
0.9\end{array}$ & $\begin{array}{l}0.4 \\
0.9\end{array}$ & $\begin{array}{l}1.8 \\
1.6\end{array}$ & $\begin{array}{l}2.4 \\
1.5\end{array}$ \\
\hline \multicolumn{7}{|l|}{ Controls } \\
\hline $\begin{array}{l}\text { Mean } \\
\text { S.D. }\end{array}$ & $\begin{array}{l}4.6 \\
1.3\end{array}$ & $\begin{array}{c}6.0 \\
0\end{array}$ & $\begin{array}{l}5.9 \\
0.3\end{array}$ & $\begin{array}{l}1.2 \\
1.2\end{array}$ & $\begin{array}{l}3.3 \\
0.9\end{array}$ & $\begin{array}{l}3.8 \\
0.4\end{array}$ \\
\hline
\end{tabular}

rent articulation $[F(1,13)=8.4, p=0.012]$. While the aphasic patients performed at a generally lower level, both patients and control subjects showed comparable effects of articulatory suppression under dual task conditions.

\section{Sentence comprehension}

The results of the individual patients on the sentence comprehension tasks are shown in Table II. In the control group, all subjects performed at ceiling level. Within the aphasic patient group, all subjects had problems with some aspects of the task.

A.K. showed slight difficulties with repeating sentences and with passive phrases. The performance of both G.T. and H.L. was characterized by minor problems with passive and meaningless phrases.

Patient B.R. achieved a maximum score with meaningful sentences. When there was no semantic structure, however, her performance was severely impaired. In addition, there was a severe deficit in matching of active and passive phrases to pictures representing the content of the sentence.

Patient L.B. was completely unable to repeat the meaningful as well as the meaningless sentences of the comprehension part. In the active/passive task, she responded correctly to five out of the eight active phrases and scored only 1 point in the passive phrase condition. This general pattern suggests that her prob- lems were less pronounced when non-verbal output was required.

\section{Paired associate learning}

The data for the paired associate learning task are presented in Table III for aphasic patients and control subjects. Repeated measures ANOVAs which were calculated separately for related and unrelated pairs yielded significant main effects of group [both $\mathrm{F}(1,13)>6.5, p<0.024$ ] and trial [linear trends: both $\mathrm{F}(1,13)>19.7, p<0.001]$. The interaction was not significant. This pattern indicates that the aphasic patients showed normal learning across trials, despite an overall lower number of correct associates.

\section{Speech rate}

Speech rate parameters in the individual patients and control subjects are presented in Table IV. In the syllable repetition task, aphasic patients were significantly slower than control subjects $(U=39.0, p=$ 0.028). Group comparisons in the spontaneous speech condition also yielded a tendency for slowing in the aphasic patients $(U=37.0, p=0.053)$. Due to missing values, the groups could not be compared on the articulation test sentences and spontaneous speech parameters. Instead, the results of the individual patients are presented in relation to the data of the control group in terms of $z$-scores. 
TABLE IV. Articulation rate

\begin{tabular}{|c|c|c|c|c|c|}
\hline Subject & $\begin{array}{l}\text { Syllable } \\
\text { repetition }\end{array}$ & $\begin{array}{l}\text { Propositional } \\
\text { sentences }\end{array}$ & $\begin{array}{c}\text { Articulation } \\
\text { test } \\
\text { sentences }\end{array}$ & $\begin{array}{l}\text { Spontaneous } \\
\text { speech }\end{array}$ & $\begin{array}{c}\text { Ranking order } \\
\text { (for more complex } \\
\text { parameters) }\end{array}$ \\
\hline \multicolumn{6}{|l|}{ Patients } \\
\hline A.K. & 0.179 & 0.467 & 0.336 & 0.14 & 1 \\
\hline G.T. & 0.221 & -1 & 0.361 & 0.222 & 2 \\
\hline H.L. & 0.167 & 0.348 & $-^{2}$ & 0.263 & 3 \\
\hline B.R. & 0.401 & -1 & 0.360 & 0.315 & 4 \\
\hline L.B. & 0.233 & $-^{2}$ & $-^{2}$ & 0.248 & 5 \\
\hline \multicolumn{6}{|l|}{ Controls } \\
\hline Mean & 0.168 & 0.166 & 0.176 & 0.167 & \\
\hline S.D. & 0.02 & 0.024 & 0.026 & 0.018 & \\
\hline
\end{tabular}

Note: mean syllable duration (in seconds) of speech segments in the four speech tasks.

${ }^{1}$ Missing value due to time restrictions.

${ }^{2}$ Missing value due to an inability to carry out the task.

Patient A.K. showed normal speech rates in the syllable repetition task $(z=0.55, p<0.25)$, but significant slowing with propositional sentences $(z=$ $12.54, p<0.001)$ and articulation test sentences $(z=6.15, \quad p<0.001)$. His spontaneous speech tended to be slowed in comparison to control subjects $(z=-1.5, p<0.06)$.

Speech rate indicated significant slowing for G.T. in all parameters that could be assessed (syllable repetition: $z=2.65, p<0.004$; articulation test sentences: $z=7.12$; spontaneous speech: $z=3.06$, both $p<0.001$ ).

Slowing of speech was observed with propositional sentences $(z=7.58, p<0.001)$ and spontaneous speech $(z=5.33, p<0.001)$ in patient H.L., but not for a parameter involving a simpler task such as repetition of single syllables $(z=-0.5, p<0.3)$. Patient H.L. failed to correctly repeat any of the nonsense sentences.

Patient B.R. showed significant slowing of speech rate relative to control data (syllable repetition task: $z=11.65$; articulation test sentences: $z=7.08$; spontaneous speech: $z=8.22$, all $p<0.001$ ). Performance on propositional sentences was not assessed.

Analysis of the speech parameters in L.B. indicated a significant slowing of speech on those parameters that could be measured (syllable repetition task: $z=$ 3.25 ; spontaneous speech: $z=4.5$, both $p<0.001$ ). The patient was unable to perform the remaining two tasks.

\section{Correlations}

For the data of the control subjects, a number of correlations were computed between speech parameters and measures of short-term memory that involved verbal presentation (digit span forward, word span, letter span). Significant or near-significant corre- lations between memory spans and speech rate parameters are plotted in Fig. 5. Longer digit spans tended to be associated with faster spontaneous speech $(r=$ $-0.65, p=0.06$ ). Letter spans (for similar letters) correlated significantly with performance on propositional sentences $(r=-0.77, p=0.02)$. Longer word spans were associated with faster speech on articulation test sentences (one syllable words: $r=-0.72, p=$ 0.03 ; three syllable words: $r=-0.64, p=0.06$ ). No other correlations approached significance.

\section{DISCUSSION}

The present study aimed to investigate the profile of short-term memory dysfunction in Broca's aphasia and to further explore the relationship between memory and motor speech processes.

The data of the control subjects provided evidence for the relevance of the phonological loop within the context of the working memory model proposed by Baddeley (1990). In this model, speech-based information is stored in a passive phonological store and its decay is prevented by reactivation within the store through articulatory rehearsal. Word length effects and articulatory suppression indicate the operation of such rehearsal processes and phonological similarity effects relate to phonological storage. All these effects were observed in control subjects in the present study, and our findings are consistent with earlier reports in the neuropsychological literature (Baddeley, 1990). Contrary to expectation, input modality (verbal vs visual) had no effect on the reproduction of words of different length. This result might be due to the particular procedure used in the present study, since subjects were allowed to read aloud the words presented visually on cards. The articulatory loop may thus have been activated directly, so that 

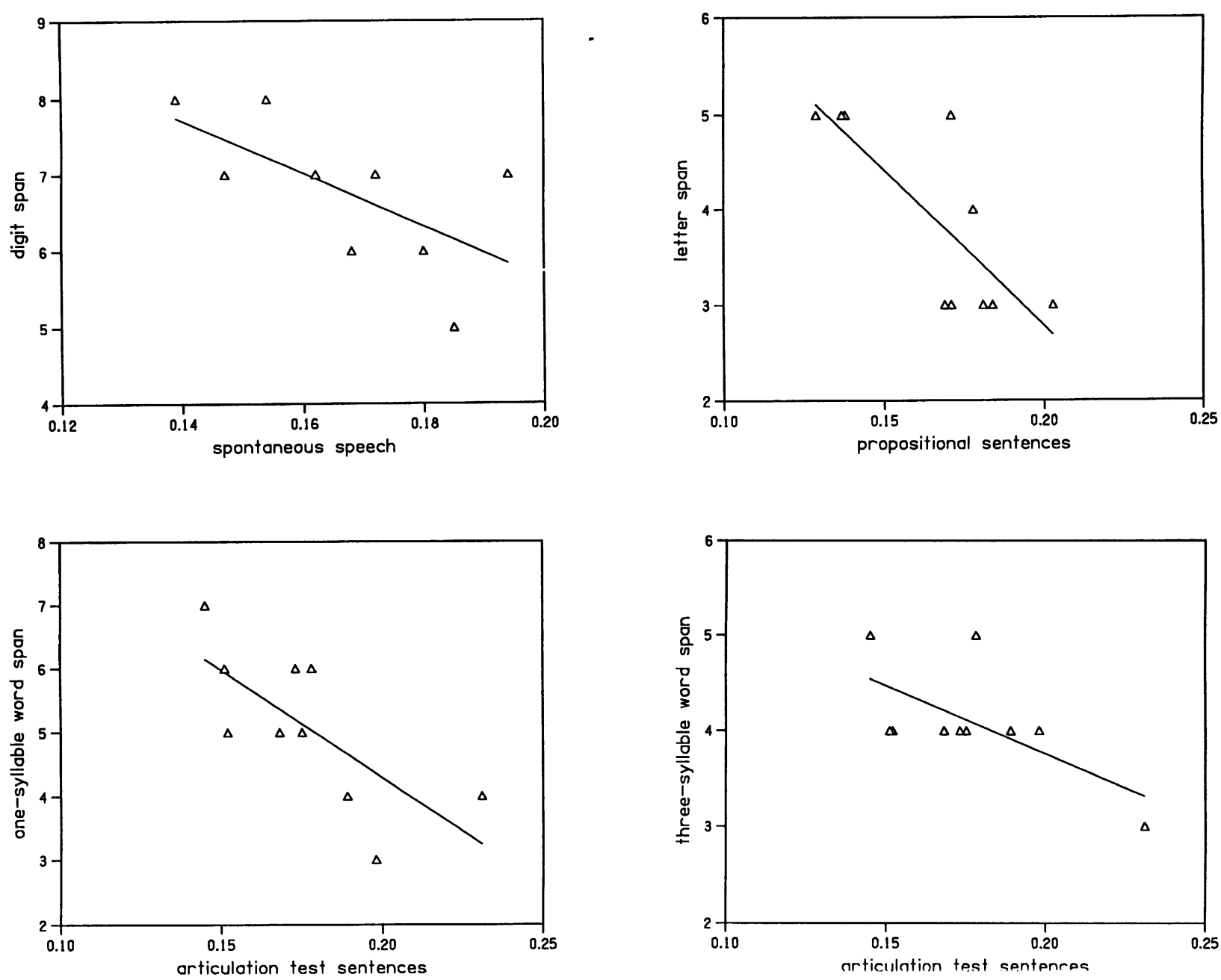

FIG. 5. Relationship between several memory spans and speech rate scores. In all graphs, speech rate is expressed in terms of mean syllable duration (seconds).

there was no need for an additional conversion of the words into a phonological code.

With respect to the word length effect, it is noteworthy that the recall of one- and two-syllable words was virtually identical, whereas recall of three-syllable words was clearly inferior. This pattern indicates that the spoken duration of the words and not only the number of syllables or letters may play a role in this respect (see Baddeley et al., 1975).

Baddeley's working memory model implies that the phonological similarity effect observed with auditorily presented lists is due to confusion of items in the phonological store, whereas word length effects relate to articulatory rehearsal. On the basis of these assumptions, Broca aphasics might be expected to show both reduced phonological similarity and word length effects, since this syndrome often involves articulatory and phonological disturbances. How- ever, in the present study, the aphasics manifested a dissociation in this regard, characterized by normal phonological similarity effects in combination with reduced word length effects. This pattern implies a rehearsal rather than a phonological store problem. Waters et al. (1992) found that the severity of impairment with respect to articulatory rate corresponds closely to the magnitude of the phonological similarity and word length effects. Comparison of motor speech data between the sample described by Waters et al. (1992) and the patients of the present study indicates that those patients who showed reduced phonological severity effects had much more severe articulatory rate problems than our subjects, i.e. they were even unable to perform the speeded word repetition task. Degree of speech motor impairment may thus explain discrepancies between the findings in different aphasic and apraxic patients. 
According to Baddeley and co-workers (1984), articulatory secondary tasks are assumed to interfere with motor speech encoding and do not produce a simple effect of attention because in normal subjects tapping has no or only little influence on span performance (see Baddeley, 1990). This finding could be replicated in the present study. Interestingly, Broca aphasics showed improved spans with tapping relative to the undistracted condition. It is conceivable that non-articulatory distraction tasks such as tapping have inherent rhythmic components that may help to compensate for errors in sequencing items within the articulatory loop system. It is well known that the use of rhythms can support memory performance in amnesic subjects and rhythms are widely used in memory therapy (Wilson and Moffat, 1984).

Correlations of speech output and short-term memory in normal subjects revealed a number of significant or near-significant results. Such associations mainly emerged if speech parameters were based on repetition of propositional or artificial sentences rather than with syllable repetition. This pattern may be attributable to the fact that the former, unlike the latter, contain a short-term memory component themselves. It should be noted, however, that because of the small number of subjects these conclusions must remain tentative and can only be seen as preliminary evidence.

A previous study suggested that patients with a more pronounced speech impairment show more marked deficits in short-term memory (see Waters $e t$ al., 1992). This notion is at least partly supported by our patient data. The correlations obtained in normals, however, restrict this association to those speech parameters assessed within more complex conditions extending beyond simple syllable repetition. For more complex parameters (i.e. speech rate conditions with the exception of the syllable repetition scores), the ranking order for the performance of the aphasic patients is displayed in Table IV. For example, patient L.B. showed the poorest performance within the patient group on both the memory tasks and the more complex speech rate measures. Where complex speech material was concerned, the performance of patient B.R. was more preserved than that of patient L.B. Consistent with this ranking, the memory performance of B.R. was slightly better than that of L.B. This overall pattern is consistent with the data of Waters and co-workers (1992) and provides further evidence for an association of shortterm memory performance and motor speech output assessed at a more complex level of language processing. In contrast, syllable repetition rate does not reflect the limits of short-term memory and might thus be more or less independent of the operation of the articulatory loop.

All aphasic patients showed markedly reduced verbal spans (digits and letters), whereas in three patients there was some evidence of spared visuospatial spans as assessed by the Corsi Blocks tests. The span data further indicate the operation of two different processes with forward and backward reproduction, respectively. Patients with Broca's aphasia showed reduced span in the backward condition irrespective of modality. Backward reproduction-in contrast to forward reproduction-involves the elaboration and transformation of stimulus input and therefore appears to be a clearer measure of working memory than forward reproduction which involves simple repetition (Schofield and Ashman, 1986). Backward reproduction of a series of spatial positions is a relatively difficult task for many subjects, and they adopt strategies to help recall, some of which may involve verbal coding of the spatial positions and their transformation in addition to the visual representation. As aphasics are likely to be less efficient in this respect than controls, they are at a disadvantage with backward reproduction of the Corsi Blocks task.

The results of the patients in the paired associates and sentence comprehension tasks point to factors other than slowed speech rate that might additionally contribute to poor short-term memory. Strategies in encoding meaningful verbal material, such as the use of semantic cues, play a role in immediate recall of more complex material such as word lists or sentences (Daum et al., 1993). The assumption that there is a semantic contribution to verbal short-term memory in addition to phonological and articulatory components has been supported by several lines of evidence, including greater spans for words relative to nonwords or increased spans for foreign language words if their meaning was known (for a summary, see Martin et al., 1994). The multiple capacity view of working memory is supported in the present study by the performance profile of Patient B.R. who was able to repeat all meaningful, but none of the meaningless sentences. Simple grammatical structure of verbal material may also aid short-term recall, as patient L.B. who scored very poorly on the speech measures performed much better on active as compared to passive sentences.

Taken together, the present results suggest that speech-based processes involving motor programming in a pre-articulatory stage may play a role in short-term memory. More specifically, such processes could be part of a rehearsal mechanism. 
Acknowledgement

This research was supported by the German Research Society (Da 259/1-2, SFB 307 and the BMFT/01KL9001.)

\section{REFERENCES}

Ackermann H and Hertrich I (1993) Dysarthria in Friedreich's ataxia: timing of speech segments. Clinical Linguistics and Phonetics, 7, 75-91.

Ackermann H and Ziegler W (1991) Articulatory deficits in Parkinsonian dysarthria: an acoustic analysis. Journal of Neurology, Neurosurgery and Psychiatry, 54, 10931098.

Baddeley AD (1986) Working Memory. Oxford Science Publications, Oxford Psychology Series No. 11. Clarendon Press, Oxford.

Baddeley AD (1990) Human Memory. Theory and Practice. Lawrence Erlbaum Associates, Hove.

Baddeley AD and Wilson B (1985) Phonological coding and short-term memory in patients without speech. Journal of Memory and Language, 24, 490-502.

Baddeley AD, Thomson N and Buchanan M (1975) Word length and the structure of short-term memory. Journal of Verbal Learning and Verbal Behavior, 14, 575589.

Baddeley AD, Lewis VJ and Vallar G (1984) Exploring the articulatory loop. Quarterly Journal of Experimental Psychology, 36, 233-252.

Basso A, Spinnler H, Vallar G and Zanobio E (1982) Left hemisphere damage and selected impairment of auditory verbal short-term memory: a case study. Neuropsychologia, 20, 263 274.

Böcher W (1963) Erfahrungen mit dem Wechslerschen Gedächtnistest (Wechsler Memory Scale) bei einer deutschen Versuchsgruppe von 200 normalen Vpn. Diagnostica, 9, 56-68.

Buckingham HW (1991) Explanations for the concept of apraxia of speech. In: Acquired Aphasia (Ed. T Sarno), pp. 271-312. Academic Press, New York.

Caplan D (1987) Neurolinguistics and Linguistic Aphasiology: An Introduction. Cambridge University Press, Cambridge.

Conrad R and Hull AJ (1964) Information, acoustic confusion and memory span. British Journal of Psychology, 55, 429-432.

Daum I, Ackermann H, Schugens MM, Reimold C, Dichgans J and Birbaumer N (1993) The cerebellum and cognitive functions in humans. Behavioral Neuroscience, 107, 411-419.

Della Sala S, Logie RH, Marchetti C and Wynn V (1991) Case studies in working memory: a case for single cases? Cortex, 27, 169-191.

Gentil M (1990) EMG analysis of speech production of patients with Friedreich's disease. Clinical Linguistics and Phonetics, 4, 107-120.

Heilman KM, Scholes R and Watson RT (1976) Defects of immediate memory in Broca's and conduction aphasia. Brain and Language, 3, 201-208.

Huber W, Poeck K, Weniger D and Willmes K (1983) Aachener Aphasie Test. Hogrefe, Göttingen.

Kolb B and Whishaw IQ (1990) Fundamentals of Human Neuropsychology. Freeman, New York.

Martin RC, Shelton JR and Yaffee LS (1994) Language processing and working memory: neuropsychological evidence for separate phonological and semantic capacities. Journal of Memory and Language, 33, 83-111.

Milner B (1971) Interhemispheric differences in the localization of psychological processes in man. British Medical Bulletin, 27, 272-277.

Schiff HB, Alexander MP, Naeser MA and Galaburda AM (1983) Aphemia: clinico-anatomical considerations. Archives of Neurology, 40, 720-727.

Schofield NJ and Ashman AF (1986) The relationship between digit span and cognitive processing across ability groups. Intelligence, 10, 59-73.

Shallice T and Butterworth B (1977) Short-term memory impairment and spontaneous speech. Neuropsychologia, 15, 729-735.

Shallice T and Warrington EK (1974) The dissociation between short-term retention of meaningful sounds and verbal material. Neuropsychologia, 12, 553-555.

Vallar G and Baddeley AD (1984) Phonological short-term store, phonological processing and sentence comprehension: a neuropsychological case study. Cognitive Neuropsychology, 1, 121-141.

Vallar G, Corno M and Basso A (1992) Auditory and visual verbal short-term memory in aphasia. Cortex, 28, 383-389.

Waters GS, Caplan D and Hildebrandt N (1991) On the structure of short-term memory and its functional role in sentence comprehension: evidence from neuropsychology. Cognitive Neuropsychology, 8, 81-126.

Waters GS, Rochon E and Caplan D (1992) The role of high-level speech planning in rehearsal: evidence from patients with apraxia of speech. Journal of Memory and Language, 31, 54-73.

Wechsler DA (1981) Wechsler Adult Intelligence Scale Revised. The Psychological Corporation, New York.

Whitty CWM (1964) Cortical dysarthria and dysprosody of speech. Journal of Neurology, Neurosurgery and Psychiatry, 27, 507-510.

Wilson B and Moffat N (1984) Clinical Management of Memory Problems. Croom Helm, Beckenham.

(Received 9 March 1995; accepted as revised 17 July 1995) 


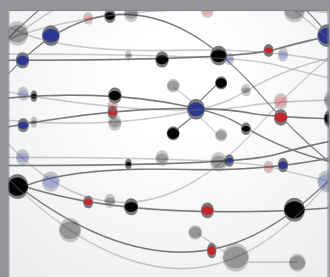

The Scientific World Journal
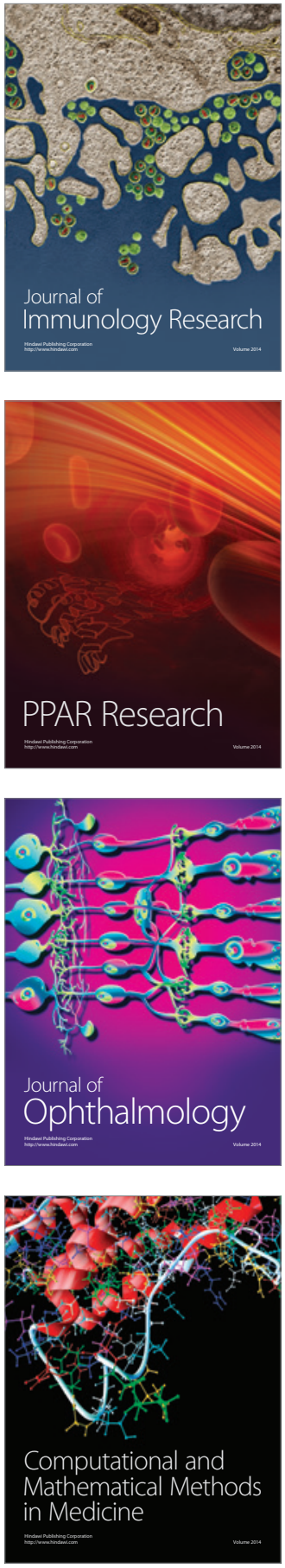

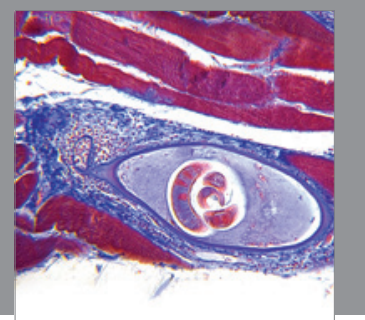

Gastroenterology

Research and Practice
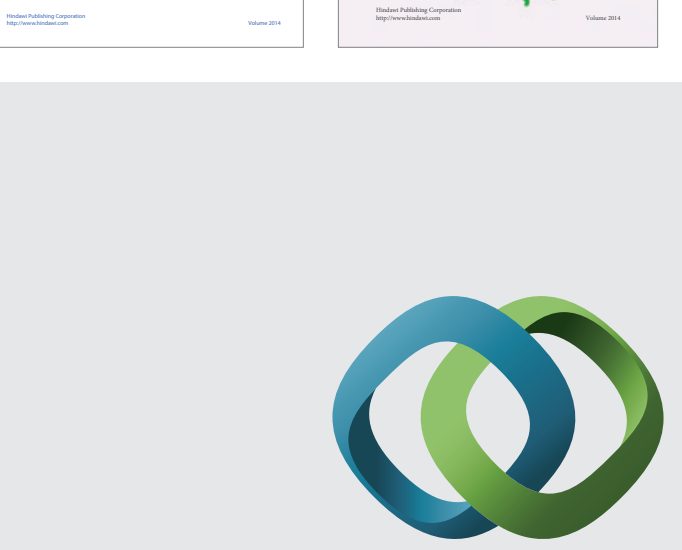

\section{Hindawi}

Submit your manuscripts at

http://www.hindawi.com
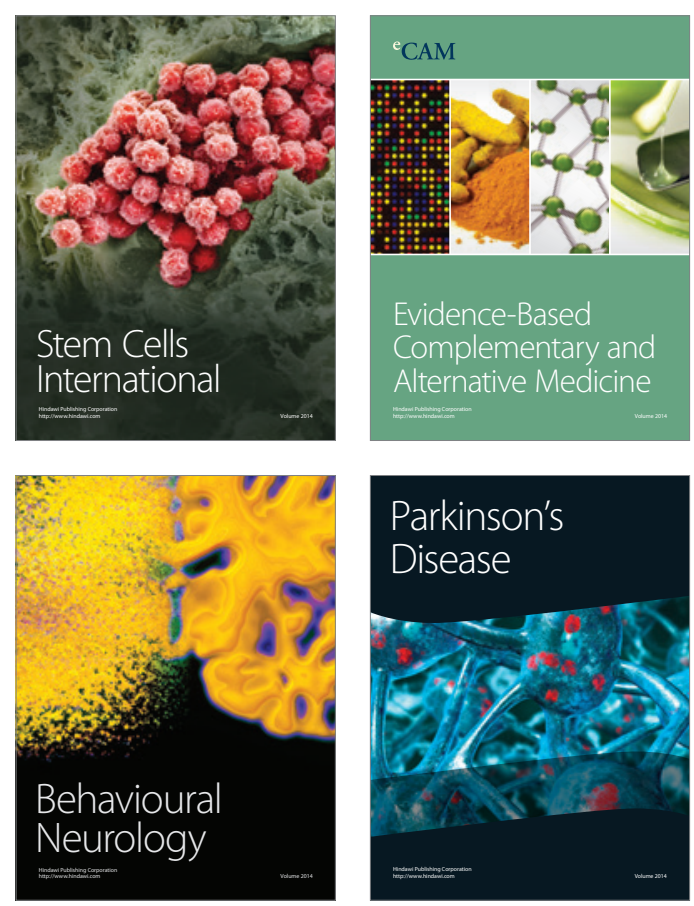

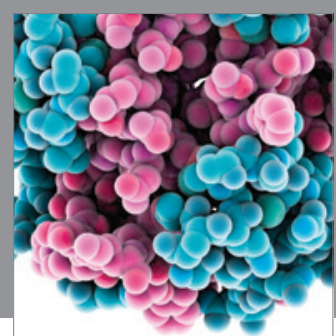

Journal of
Diabetes Research

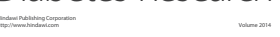

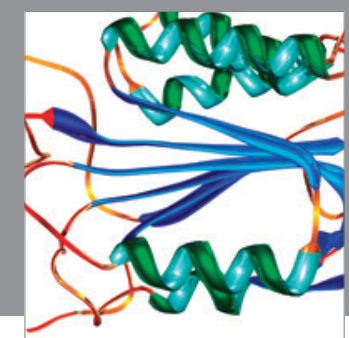

Disease Markers
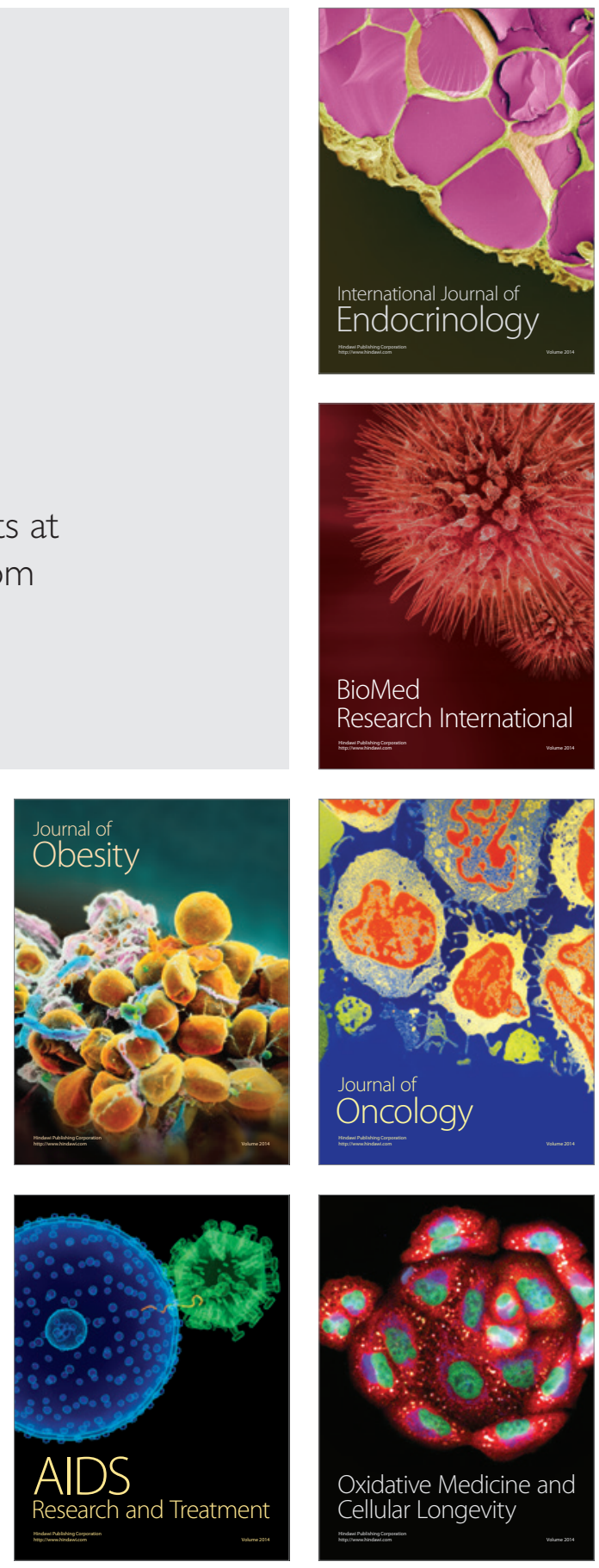